\title{
Empirical Study of the Risks and Difficulties in Implementing Guaranteed Maximum Price and Target Cost Contracts in Construction
}

\author{
Daniel W.M. Chan, M.ASCE ; Albert P.C. Chan ${ }^{2}$; Patrick T.I. Lam³ \\ and James M.W. Wong ${ }^{4}$
}

1 Assistant Professor, Department of Building and Real Estate, The Hong Kong Polytechnic University, Hung Hom, Kowloon, Hong Kong, China

${ }^{2}$ Professor and Associate Head, Department of Building and Real Estate, The Hong Kong Polytechnic University, Hung Hom, Kowloon, Hong Kong, China

3 Associate Professor, Department of Building and Real Estate, The Hong Kong Polytechnic University, Hung Hom, Kowloon, Hong Kong, China

${ }^{4}$ Postdoctoral Fellow, Department of Civil Engineering, The University of Hong Kong, Pokfulam Road, Hong Kong, China 


\title{
Empirical Study of the Risks and Difficulties in Implementing Guaranteed Maximum Price and Target Cost Contracts in Construction
}

\begin{abstract}
:
Over the past few decades, both the guaranteed maximum price (GMP) and target cost contracting (TCC) arrangements have been regarded as alternative integrated procurement strategies for clients to mitigate risks, minimize claims, integrate the diverse interests of a complex construction project and offer incentives to provide value-added services. However, the adoption of GMP/TCC contracts may also generate significant risks and difficulties that merit considerable attention. This paper aims to provide a concise review of the potential pitfalls of GMP/TCC scheme in general, and identifies the key risk factors and potential difficulties associated with GMP/TCC in comparison with other procurement strategies in construction in particular via an empirical survey of clients, contractors and consultants in Hong Kong. The survey data gleaned from 45 valid replies were analyzed using the mean score ranking technique, Kendall's concordance test and Spearman's rank correlation test. The survey results indicated that 'Involvement of inexperienced or claimconscious contractors in a project procured by a GMP/TCC contract' was considered to be the most significant risk factor; whilst 'Design development must keep pace with main contractor's program for tendering the domestic subcontractors' works packages' as the major difficulty in implementing GMP/TCC projects. The research findings derived from this study are particularly essential in assisting the contracting parties to mitigate the detriments brought about by potential risks or difficulties when embarking on GMP/TCC contracts. It has also generated valuable insights into developing effective recommendations for alleviating the barriers to GMP/TCC success for future construction projects.
\end{abstract}

Keywords: Guaranteed maximum price; Target cost contracting; Pitfalls; Risks; Difficulties; Hong Kong. 


\section{Introduction}

Some alternative integrated forms of procurement have appeared within the construction industry since the 1990s to fulfill the emerging needs of clients and to enhance overall project performance (Masterman 2002). Amongst them, incentivization measures have been launched with success in the United States, United Kingdom and Australia, to integrate the diverse interests of a complex construction project, mitigate risks, minimize claims and to motivate service providers to offer "value-added" services in project outcomes (Construction Industry Review Committee 2001). Previous overseas successful cases substantiated that both the guaranteed maximum price (GMP) and target cost contracting (TCC) procurement approaches, serving as a cost incentive mechanism, can provide several mutual benefits to all of the contracting parties, if they are properly structured, implemented and managed (Trench 1991; Walker et al. 2000). The New Engineering Contract which includes various target cost contract options has been adopted in the engineering and construction sectors throughout the United Kingdom and overseas for many years (Broome and Perry 1995; Perry 1995).

Since GMP/TCC is still relatively new within the Hong Kong construction industry, an extensive industry-wide investigation of the key risk factors and potential difficulties in implementing GMP/TCC in comparison with other procurement options is considered to be essential and contemporary, in that any lessons learnt from Hong Kong would be of international interest and reference. This paper attempts to identify the underlying risk factors and potential difficulties with the prevailing practices of GMP/TCC through an empirical questionnaire survey targeting different relevant project stakeholders with direct hands-on experience with GMP/TCC in Hong Kong. The research outcomes from this study have provided useful insights for improvement by mitigating the effect of risk factors and occurrence of potential difficulties of GMP/TCC scheme for future construction projects.

\section{Definitions and Characteristics of GMP/TCC}

GMP/TCC is an incentive-based procurement strategy which will reward the contractor for any savings made against the guaranteed maximum price or target cost and penalize him when this sum is exceeded as a result of his own mismanagement or negligence 
according to a pre-agreed share ratio (Masterman 2002). The contractor usually includes a sum for future design development in the form of GMP/TCC allowance and for any unforeseeable risks associated with the project in the tender (Gander and Hemsley 1997).

The National Economic Development Office (United Kingdom) - Civil Engineering (1982) defined TCC as: "Target cost contracts specify a best estimate of the cost of the work to be carried out. During the course of the work, the initial target cost will be adjusted by agreement between the client or his nominated representative and the contractor to allow for any changes to the original specification. Any savings or overruns between target cost and actual cost at completion are shared between the parties to the contract with a predetermined share ratio according to the contract conditions." Some researchers even conducted research on how the clients and contractors set the best cost-sharing fraction in target cost contracts in construction (e.g. Perry and Barnes 2000; Broome and Perry 2002).

Carty (1995) defined GMP to be: "The contractor and owner agree that the contractor will perform an agreed scope of work at a price not to exceed an agreed upon amount, the guaranteed maximum price $(G M P)$..... if the final actual cost and the agreed upon contractor's profit are less than the GMP, the owner and contractor will share the savings in cost based on an agreed upon formula. If the final actual cost exceeds the GMP without any changes to the defined scope, the contractor must solely bear the additional cost but not the owner." Hence, GMP can be regarded as one of the forms of TCC with the sharing arrangement limited solely to the gain (Perry and Thompson 1982). An agreed ceiling price and a gain-share/pain-share mechanism of a project are established in the construction contract under this agreement (Clough and Sears 1994; Cantirino and Fodor 2003). This is a unique arrangement that shifts from the fixed price approach to a target cost approach based on joint determination and agreement between the contractor and the client on the allocation of shared risks.

Apart from the ceiling price and gain-share/pain-share mechanism for the project, the valuation of variations is another key feature of the GMP/TCC arrangement. In a typical GMP/TCC construction project, two types of variations are often pre-defined under the conditions of contract: (1) design development variations (i.e. non GMP/TCC variations); and (2) GMP/TCC variations (Gander and Hemsley 1997). The design development variations do not trigger a re-calculation of the GMP or target cost because they are 
deemed to be included in the fixed lump sum of main contractor's direct works finalized at the main contract award. However, GMP/TCC variations can allow for the re-calculation of the GMP or target cost due to: (1) changes in scope of work such as change in floor area or volume; (2) change in function of an area; (3) change in quality of an area; (4) adjustment of provisional quantities or provisional sums; (5) corrected quantity errors by consultants; and (6) unexpected additional fees or charges imposed by statutory authorities (Fan and Greenwood 2004; Hong Kong Housing Authority 2006). Extras should therefore be related to scope changes requested by the client. The net cost adjustment of such GMP/TCC variations will be added to (for 'addition' work) or subtracted from (for 'omission' work) the contract GMP or target cost.

\section{Literature Review on the Risks of GMP/TCC}

Risks are perceived as the possible exposure to economic loss (Stuckhart 1984) and should be identified and analyzed before the appropriate response is determined (Broome and Perry 2002). Although the GMP/TCC procurement approach has been implemented in a number of construction projects for several years, some of the projects have been exposed to very high risks or uneven allocation of risks. Table 1 summarizes the key risk factors inherent with the GMP/TCC approach as sought from relevant reported literature including textbooks, research reports, academic journals, conference proceedings and internet materials with the corresponding frequencies of their citations.

\section{Table 1. Summary of the key risks of GMP/TCC}

\section{Financial Risks}

The GMP or target cost is not definitely a 'guaranteed' or 'maximum' price, as it will be adjusted in case of unforeseen changes that occur as part of the construction work (Uebergang et al. 2004). The client may take certain financial risks of paying over the ceiling price once the scope change is considered to be a GMP/TCC variation (Perry and Barnes 2000). The client may also carry the risk of paying variations more than under the traditional procurement method because the contractor may attempt to inflate the estimated costs of work, thereby gaining the maximum advantage where prospective savings can be achieved (Baldwin and McCaffer 1991; Gander and Hemsley 1997). Perry 
and Barnes (2000) also emphasized that the TCC approach requires the client to carry more risks than conventionally priced contracts because of incomplete design at tender stage. If a plethora of changes are expected in the project, the client is not advised to adopt GMP/TCC as this may cause expensive, intractable claims.

The GMP provision clearly involves the contractor in increased financial risk as the excess costs over the GMP due to uncertainties arising from site conditions would be solely absorbed by him (Stuckhart 1984). The contractor also has to bear the risks of unforeseen ground conditions, design development and compliance with performance specifications, for which he may earn lower profit or even incur a loss due to unclear definition of the scope of work (Fan and Greenwood 2004). The contractor would thus include additional mark-up to their tender price, as additional works or scope change can be claimed only if they are assessed to be GMP/TCC variations. Sadler (2004) therefore advocated that TCC is regarded as a more equitable risk sharing approach owing to the presence of pain-share mechanism. Hence, GMP contracts may induce a higher initial tender price since the contractor is solely responsible for bearing the risk of cost overrun if alleged changes to the defined scope of work are not justified as GMP variations (Chevin 1996). In other words, the client gains a degree of cost certainty, but the price is usually not the lowest price. However, if a fixed price is more important than ascertaining the lowest price in a project, a GMP/TCC contract may be the favorable answer.

\section{Dispute Risks}

Under the GMP/TCC form of project delivery, disputes may arise during the design development phase and construction phase of the works as to which architects/engineers instructions constitute GMP or target cost variations or which are deemed to be design development (Hong Kong Housing Authority 2006). The employer may regard any design variations as entirely at the risk of the contractor, while the contractor may contend that certain changes fall outside the original scope of work and their additional costs should be claimable (Fan and Greenwood 2004). This is thus potentially the largest 'gray' area for disputes, particularly if the target cost is established early during the design process (Tay et al. 2000). Disputes would be inevitable with this procurement approach because there is a lack of clarity as to whether a change should be considered to be a variation to the target cost or not (Chevin 1996). The occurrence of disputes therefore essentially depends on 
how well the client develops the outline design of project with clear scope of work at project commencement.

Furthermore, as the GMP/TCC approach is being developed in Hong Kong, the experience of applying this procurement method is still relatively scarce. If inexperienced or claimconscious contractors are appointed, there is a potential danger for the contracting parties to become confrontational (Hong Kong Housing Authority 2006). Hence, contractors must be fully conversant with the underlying principles of GMP/TCC and be prepared to recognize the risks they have taken on board with GMP/TCC contracts (Fan and Greenwood 2004). Besides, the lack of standard form of contract for GMP/TCC procurement arrangement may be conducive to misunderstanding of liabilities between various project stakeholders (Gander and Hemsley 1997). This might jeopardize the application of target cost procurement strategy in the local context.

\section{Literature Review on the Difficulties of GMP/TCC}

A review of the contemporary literature indicates that there are a multitude of common difficulties encountered in implementing GMP/TCC concepts. Table 2 shows the matrix of the identified difficulties and the corresponding frequencies of their citations.

Table 2. Summary of the potential difficulties in implementing GMP/TCC

\section{Unclear Definition of Change in Scope of Work}

The major potential problem with implementing the GMP/TCC approach is the unclear definition of a scope change (Gander and Hemsley 1997; Tay et al. 2000). Vague explanations on any scope changes may cause disputes with the natural tendency of the client and contractor pulling in opposite directions to achieve their own objectives (Cheng 2004; Fan and Greenwood 2004). The tendency of the contractor is to view variations as a 'scope change' to maximize his opportunity of securing extra payment whereas the client wishes to keep as many changes as possible under 'design development' to minimize cost increase, not to mention a desire to achieve potential cost savings. Tang and Lam (2003) stressed that it is difficult to evaluate the revised contract price when an alternative design is proposed by the contractor and it takes time to reassess the cost implication. Tay et al. 
(2000) also expressed that this is an aspect of GMP/TCC that is very difficult to administer. Hence, the GMP/TCC scheme might not be an appropriate procurement form for contracts where many changes are expected or it would be difficult to define the scope of work early (Trench 1991).

\section{Higher Cost Premium for GMP/TCC}

In general, the contractor under the GMP/TCC style of procurement takes on more responsibilities than the traditional approach and has included in his tender an allowance for design development and unforeseeable risks (Sadler 2004). One common response is for the general contractor to simply pass the risks down the line to the subcontractors (Lewis 2002). This may then inflate the bid price for the contractor to commit to the guaranteed price by covering additional risks. In the majority of cases, tenders for GMP contracts may lie between $1 \%$ and $3 \%$ higher than equivalent tenders sought under a JCT 80 standard form of contract with quantities under favorable conditions where the contract sum is the de-facto guaranteed maximum price (Mills and Harris 1995). That is, the client maintains a degree of cost certainty, but the price is often not the lowest price. However, where a fixed price is more essential than securing the lowest price, a GMP/TCC contract may be the desirable option.

\section{Greater Commitment by Project Stakeholders}

The GMP/TCC approach requires a greater level of commitment and involvement by all project parties to the contract arising from the methodology of tendering, not only for the main target cost contract, but also individually for the domestic subcontractor's works packages (Tang and Lam 2003). The client has to be more involved and closely monitor the project when procuring GMP/TCC contracts because the design is still being developed after the contractor has committed to a ceiling price (Sadler 2004). The design development should always keep in good progress with the main contractor's program for tendering domestic subcontractor's works packages, otherwise potential delay may arise. These additional administrative requirements might result in the relevant parties having to commit more personnel to the project, together with the potential higher consultant fees to be incurred by design consultants in evaluating tenders for specialist subcontracts after the award of main contract (Hong Kong Housing Authority 2006). 


\section{Unfamiliarity with GMP/TCC Methodology}

The GMP/TCC form of procurement is a rather new concept within the local construction industry. Project stakeholders unfamiliar with the corresponding contractual arrangement may easily generate arguments between contracting parties (Cheng 2004). Project participants may not be used to adapt to this novel way of working (e.g. joining force between a team of design consultants and main contractor in design work) and may find it uncomfortable and difficult to change the traditional style they work (Sadler 2004). Difficulties have often been experienced in setting a genuine agreed maximum price or target cost; monitoring the ceiling price as changes to the work occur; setting allowances for design development and unexpected risks; and determining the cost-sharing formula of GMP/TCC projects. Gander and Hemsley (1997) also asserted that the absence of standard form of GMP/TCC contract would result in a greater possibility of drafting errors and omissions in tender documents and misunderstanding of liabilities between the collaborative parties. It is a complicated form of contractual agreement and some projects do not warrant the administrative efforts and support that are required to set up and implement this form of contract (Sadler 2004).

\section{Research Methodology}

An industry-wide empirical questionnaire survey was conducted between May and June of 2007 to seek the opinions of various key project stakeholders in Hong Kong on the risks and difficulties encountered with GMP/TCC contracts. Based on the contemporary literature and a series of previous face-to-face interviews (Chan et al. 2007), a total of 10 key risk factors together with 12 potential difficulties of GMP/TCC were identified, which formed the basis of the empirical survey questionnaire. Respondents were invited to rate each of the identified risk factors and difficulties according to a five-point Likert scale delineating various levels of agreement $(1=$ strongly disagree; $3=$ neutral and $5=$ strongly agree) with reference to a specific GMP/TCC project they had participated in. Respondents were also requested to list out and score any other unmentioned risks and difficulties derived from their personal discretion and actual experience but no new items were obtained from them. 
Local industrial practitioners, including those from the client organizations, consultants, main contractors and subcontractors, who have gained extensive hands-on experience in GMP/TCC construction projects in Hong Kong were the target respondents of the questionnaire survey. In this research, data were gleaned through direct distribution of empty survey questionnaire from the senior staff of corresponding client organizations to the representatives of their project consultants, main contractors and subcontractors, together with the full support of the Association for Project Management, Hong Kong Branch (APM-HK) and the Construction Industry Institute, Hong Kong (CII-HK). A total of 139 self-administered blank survey forms were distributed to individual industrial practitioners involved with GMP/TCC projects, by means of postal mail and electronic mail. Follow-up telephone calls and electronic communications were undertaken where possible to elicit more detailed responses and/or provide further clarifications for any unclear / misunderstood items on the survey form.

Altogether, 45 valid completed survey forms were received, yielding a response rate of 23.6\%. A total of $14 \mathrm{GMP} / \mathrm{TCC}$ construction projects had been covered in the questionnaire survey, which could substantially represent the GMP/TCC project population in Hong Kong over the past decade of 1998-2007. Given that GMP/TCC is a relatively new contractual arrangement being adopted in Hong Kong, this level of response rate was regarded as acceptable and adequate for further statistical analysis. The 45 returned questionnaires included various industry stakeholders: clients (16 respondents), consultants (13 respondents), main contractors (12 respondents) and subcontractors (4 respondents). Respondents were also categorized into three various key survey groups for further analysis and comparison, i.e. client group, consultant group, together with main contractor plus subcontractor group). Thus, it is believed that each of the three groups were adequately represented in the survey.

Most of the respondents held a senior position in their organizations with abundant experience in the construction sector. All of the respondents have already acquired over 10 years of working experience within the construction industry with over $62 \%$ of them having more than 20 years. Regarding the experience with GMP/TCC, over $90 \%$ of the respondents possessed direct hands-on experience in one or more GMP/TCC projects. Merely 4 out of 45 respondents (8.9\%) had no hands-on practical experience but with sound understanding of GMP/TCC scheme or principles. Hence, all of the respondents 
were well-experienced professionals in the construction practice who should be able to provide reliable information and genuine opinions to the research.

\section{Tools for Data Analysis}

\section{Mean Score Ranking Technique}

Non-parametric statistical techniques were adopted to analyze the quantitative data acquired from the questionnaire survey. Descriptive statistics and 'mean score' ranking technique (Chan et al. 2003) were applied to establish the relative significance of various risks and difficulties of GMP/TCC using the Statistical Package for Social Sciences (SPSS). Respondents were further categorized into three various key survey groups as classified according to their roles involved in a project (i.e. whether client group, contractor group or consultant group) for generating more meaningful cross-comparisons on the risks and difficulties of GMP/TCC. The consultant group comprised project consultants from various disciplines (i.e. architectural, engineering and quantity surveying) while the contractor group was made up of both main contractors and subcontractors. The five-point Likert scale described previously was used to calculate the mean score for each risk or difficulty, which was then used to determine their relative rankings in descending order of significance. These rankings made it possible to cross-compare the relative significance of the risks or difficulties across different groups of respondents.

\section{Cronbach's Alpha Reliability Test}

The Cronbach's alpha reliability (the scale of coefficient) measures were employed to examine the internal consistency amongst the responses under the adopted Likert scale of measurement regarding the identified risks and difficulties of GMP/TCC (Sanotos 1999; Norusis 2002). The Cronbach's alpha coefficients range from 0 to 1 in value and may be used to describe the reliability of factors extracted from dichotomous and/or multi-point formatted questionnaires or scales (Sanotos 1999). If the items making up the score are all identical and perfectly correlated, then $\alpha=1$. If the items are all independent, then $\alpha=0$. Therefore, the higher the score, the more reliable the generated scale will be. The Cronbach's alpha tests were applied to test the reliability of the scales of the risks and 
difficulties of the GMP/TCC practices in the questionnaire survey.

\section{Kendall's Concordance Analysis}

The Kendall's coefficient of concordance $(W)$ was applied to measure the agreement of different respondents on their rankings of risks and difficulties based on mean values within a particular survey group (Siegel and Castellan 1988). This statistical analysis aims to check whether the respondents within an individual group respond in a consistent manner or not. If the coefficient $(W)$ was statistically significant at a pre-defined significance level of say $5 \%(0.05)$, then the null hypothesis that the respondents' sets of rankings are unrelated (independent) to each other within a survey group could be rejected. In other words, there would be a reasonable degree of consensus amongst the respondents within the group on the rankings of the risks or difficulties (Daniel 1978). Thus, a high or significant value of $W$ manifests that different parties are essentially applying the same standard in ranking the risks or difficulties.

\section{Spearman's Rank Correlation Test}

The level of agreement between any two survey groups on their rankings of the risks and difficulties encountered in adopting the GMP/TCC scheme was measured by the Spearman's rank correlation coefficient $\left(r_{s}\right)$. The coefficient $\left(r_{s}\right)$ ranges between -1 and +1 . A value of +1 denotes a perfect positive linear correlation whereas negative values indicate negative linear correlation meaning that low ranking on one is associated with high ranking on the other. If the correlation is close to 0 , then it implies that no linear relationship exists between the two groups on the variable (Albright et al. 2006). If $r_{s}$ was statistically significant at a pre-determined significance level of 0.05 (i.e. the actual calculated p-value $<$ the allowable value of 0.05 ), then the null hypothesis that no significant correlation between the two groups on the rankings can be rejected, implying no significant disagreement between the two sets of rankings.

\section{Presentation and Discussion of Research Findings}

The results derived from the analysis of empirical questionnaire survey were crossreferenced to the published literature and to complement each other for validation. 


\section{Risk Factors Inherent with GMP/TCC}

\section{Overall ranking of the risks of GMP/TCC}

It should be emphasized that the ranking exercise is based on perception, not an objective assessment. A subjective assessment of the ranking result is made to analyze the perceived relative importance of the risks and difficulties in relation to the GMP/TCC procurement strategy. The fact that this subjective assessment does not provide any absolute value on the ranking position is recognized. Emphasis is then given only to those benefits that are placed as the most important and the least important in the ranking list (Chan and Kumaraswamy 1996).

The Cronbach's alpha coefficient for the rated 'risks' is 0.757 ( $F$ statistics $=13.338, p=$ 0.000) implying that the scale used for measuring these parameters is reliable at the 5\% significance level. Table 3 gives the summary of the rated key risk factors of implementing the GMP/TCC approach as perceived by the survey respondents. As discerned from Table 3 , altogether there are 7 risk factors out of 10 having mean scores larger than 3, indicating a general agreement of "significance" with those risk factors. Amongst the 7 agreed risk factors, 'Involvement of inexperienced or claim-conscious contractors in a project procured by a GMP/TCC contract' was considered to be the most significant risk factor (Mean $=3.89 ; \mathrm{SD}=0.895)$, because they might jeopardize the entire project delivery process of GMP/TCC. This risk has also been alerted and supported by Cheng (2004), Tang (2005) and the Hong Kong Housing Authority (2006). Hence, a right selection of project team is essential in engendering mutual trust, facilitating effective communication, efficient co-ordination and productive conflict resolution (Chan et al. 2002). Gander and Hemsley (1997) suggested that the recruitment of an experienced, competent project team is crucial to the success of a GMP/TCC project, as inexperienced GMP/TCC contractors can always stumble due to a lack of clarity regarding their responsibilities.

The National Economic Development Office (1982) from the United Kingdom also opined that the success of GMP/TCC contracts is closely related to the managerial efforts expended by various collaborative parties in formulating and administering the contract. A claim-conscious contractor always thinks about increasing his profit margins by alleging 
any changes to the project as GMP/TCC variations rather than trying to minimize the cost of work (Baldwin and McCaffer 1991; Gander and Hemsley 1997), then the underlying merits of GMP/TCC would be diminished leading to a failure of the entire project. Besides, the gray area between design development variations and GMP/TCC variations may likewise provide possible opportunities for contractor to seek extra payments from the client due to substantiated claims. This might jeopardize the application of target cost procurement strategy. Therefore, contractors must be fully conversant with the governing principles of the GMP/TCC contracting approach and be prepared to recognize the risks they have taken on board (Fan and Greenwood 2004).

In addition, the risk factor 'Disputes may arise due to the change in the scope of work' $($ Mean $=3.80 ; \mathrm{SD}=0.869)$, together with 'Contractor may not foresee design development risks thus taking more risks' $($ Mean $=3.60 ; \mathrm{SD}=0.939)$ due to unclear scope of work in the client's project brief and incomplete design at the tender stage (Patterson 1999; Tay et al. 2000), were also scored as the second and third most significant in GMP/TCC respectively. Contractors should well understand the potential risks which may be derived from any undescribed work in contract, design development and tender bids of their subcontractors (Mills and Harris 1995; Fan and Greenwood 2004).

Other risk factors being perceived as significant with mean value larger than 3 included Item 6 'No standard form of GMP/TCC contract leads to misunderstanding of roles and liabilities between contracting parties' $($ Mean $=3.49 ; \mathrm{SD}=0.920)$, which was also stressed by Gander and Hemsley (1997). Both Item 5 'Contractor may earn lower profit or even incur a loss' (Mean $=3.45$; SD $=1.022$ ) and Item 7 'Difficult to use successfully on contracts where many changes are expected' (Mean $=3.38 ; \mathrm{SD}=1.211$ ) are primarily caused by unclear definition of scope of work in the client's project brief conducive to potential disputes (Chevin 1996; Chan et al. 2007). Lastly, Item 2 'Difficult to evaluate the revised contract price when an alternative design is proposed by the contractor' (Mean = 3.13; $\mathrm{SD}=1.036$ ) would take more time for design consultants to administer and to reassess the cost of the entire project (Tang and Lam 2003).

\section{Agreement of respondents within each survey group}

The key risk factors of GMP/TCC were also assessed from different perspectives of the 
client group, contractor group and consultant group. As all of the key active players in adopting GMP/TCC had been included in the questionnaire survey, it was considered that the opinions and findings could substantially represent the GMP/TCC project pool in Hong Kong over the past decade of 1998-2007. Although the number of respondents drawn from each of the three respondent groups was limited, the research findings were still considered valid and representative given the scarce number of construction projects procured with the GMP/TCC approach in Hong Kong (about 20 as cited by Chan et al. 2007).

The rankings derived from each of the respondent groups were transformed into a matrix as the imported data for the calculations of the Kendall's coefficients of concordance $(W)$ as shown in Table 4. The Kendall's coefficient of concordance (W) for the rankings of risks was $0.249,0.173,0.445$ and 0.332 for 'all respondent group', 'client group', 'contractor group' and 'consultant group' respectively. The computed W's were all significant with $p=0.005$.

As the number of factors considered was greater than seven, the chi-square value would be referred to rather than the $W$ value as advocated by Siegel and Castellan (1988). According to the degree of freedom $(10-1=9)$ and the allowable level of significance [5\% as adopted by Chan et al. (2003)], the critical value of chi-square from table was found to be 16.92. For all of the four groups ('all respondent group', 'client group', 'contractor group' and 'consultant group'), the actual computed chi-square values (98.60, 23.36, 64.08 and 38.84 respectively) were all above the critical value of chi-square of 16.92. This result indicates the null hypothesis that 'There is no significant agreement amongst different respondents on the rankings within a particular group' has to be rejected. Therefore, there is sufficient evidence to conclude that there is significant degree of agreement amongst the respondents within each group on the rankings of the risk factors of GMP/TCC.

\section{Agreement of respondents between survey groups}

After establishing the internal consistency of the rankings within all respondent group and within each of the three respondent groups, the subsequent stage of analysis was to test the consensus on the ranking exercise amongst the respondents across the three various groups 
using the Spearman's rank correlation test as reported in Table 5.

The survey findings revealed that the null hypotheses that there is no significant correlation between clients-consultants and contractors-consultants on the rankings of risks associated with the GMP/TCC scheme can be rejected at the 5\% significance level. Hence, there is adequate evidence to conclude that there is no significant disagreement between these two groups of respondents on the ranking exercise. In particular, regarding the comparison of rankings between client group and consultant group, the top three, 6th and 10th risk factors were ranked as the same by both groups because the team of consultants always acts on behalf of the client and works together to look after a project from inception stage up to commissioning stage (Chan and Kumaraswamy 1996) and thus they may always share similar opinions. With reference to the comparison of rankings between contractor group and consultant group, the lowest four ranked risk factors (i.e. ranked as 7 th to 10th) were almost the same for both groups. This reflects the apparent congruent opinions on the relative importance of the risks associated with GMP/TCC between these two respondent groups.

However, this null hypothesis between the client group and contractor group cannot be rejected at the 5\% significance level. This indicates that the diverse perceptions on the risks inherent with GMP/TCC between these two respondent groups. For example, while the client group considered Item 3 'Inexperienced or claim-conscious contractors jeopardize the GMP/TCC process' as the top risk factor, the contractor group ranked it as the 4th. This apparent disagreement is attributed to the different roles and expectations from a GMP/TCC project between clients and contractors. Clients are often very concerned about the appointment of an experienced, competent contractor to work together on a GMP/TCC project for achieving success (Tang 2005; Hong Kong Housing Authority 2006), whereas contractors themselves do not perceive it as a major risk because they always think that they are confident and experienced enough in undertaking GMP/TCC projects if appointed. Moreover, the client group ranked Item 9 'Client may carry more risks than the traditional procurement system' as the 5th risk factor, but the contractor group ranked it as the 10th. Clients may shoulder more risks due to incomplete design at tender stage (Perry and Barnes 2000) and lots of subsequent changes to the project may be assessed as GMP/TCC variations (Gander and Hemsley 1997; Uebergang et al. 2004) under which the client is required to pay extra money to the contractor for 
compensation.

Another two conspicuous disparities were observed from Item 6 'No standard form leads to misunderstanding of liabilities between parties' which was ranked as the 1st by contractor group but significantly lower (8th) by client group; and Item 5 'Contractor may earn lower profit or even incur a loss due to unclear definition of the scope of work' again ranked as the 1st by contractor group but considerably lower (7th) by client group. Lack of standard form of contract for GMP/TCC scheme may be conducive to misunderstanding of roles and responsibilities between various project stakeholders (Gander and Hemsley 1997), especially in this complicated form of contractual arrangement to involve the contractor in design development process. Furthermore, the contractor would solely bear the risk of cost overrun if any potential changes in the scope of work or additional works are not justified to be GMP/TCC variations (Chevin 1996; Mills and Harris 1995). Therefore, the contractor group ranked them as the two most important risk factors.

Table 3. Key risk factors of GMP/TCC in Hong Kong (all respondents)

Table 4. Ranking and Kendall's coefficient of concordance for the key risk factors of GMP/TCC

Table 5. Spearman's rank correlation test between groups of survey respondents on the key risk factors of GMP/TCC

\section{Difficulties in Implementing GMP/TCC}

\section{Overall ranking of the difficulties of GMP/TCC}

The Cronbach's alpha coefficient for the rated 'difficulties' is 0.737 ( $F$ statistics $=14.953$, $p=0.000$ ) revealing that the scale used for measuring the potential difficulties is reliable at the 5\% significance level. Table 6 shows the relative importance of those potential difficulties in implementing the GMP/TCC scheme as perceived by the survey respondents. A total of 8 difficulties out of 12 have their mean scores larger than 3, implying a general agreement of "significance" with those difficulties. Interestingly, all of the three survey groups believed and ranked 'Design development must keep pace with main contractor's program for tendering the domestic subcontractor's works packages' and 'Clients had to 
be more involved in a project' as the top two problems with GMP/TCC, with the mean values of $4.03(\mathrm{SD}=0.628)$ and $4.02(\mathrm{SD}=0.758)$ respectively.

If the design development progress cannot keep up with main contractor's program for tendering the domestic subcontractor's works packages, potential delay may occur (Hong Kong Housing Authority 2006). Unclear explanations on any scope changes may provoke intractable disputes with the natural tendency for the client and the contractor pulling in opposite directions to achieve their own objectives (Cheng 2004; Fan and Greenwood 2004). Moreover, the client has to be more closely involved and monitor the GMP/TCC project because the design is being developed after the contractor has committed to a ceiling price (Sadler 2004). The GMP/TCC scheme requires a greater level of commitment and involvement by all collaborating parties to the contract arising from the methodology of tendering, not only for the main target cost contract, but also individually for the domestic subcontractor's works packages (Tang and Lam 2003).

Furthermore, 'Disputes over whether Architects/Engineers Instructions constituted GMP/TCC variations or were deemed to be design development' was also highly rated as the third most important difficulty in managing GMP/TCC projects (Mean $=3.79$; $\mathrm{SD}=$ 0.910), as echoed by the interview findings from Chan et al. (2007). Under the conditions of GMP/TCC contracts, design development variations would not instigate an adjustment of the GMP value or target cost because they are deemed to have been covered in the fixed lump-sum price of main contractor's direct works, but GMP/TCC variations can arise due to changes in the scope of work (Fan and Greenwood 2004; Hong Kong Housing Authority 2006). Because of unclear scope of work in the client's project brief, the contractor very often tends to see any variation as a 'scope change' to maximize his opportunity of obtaining extra payment whereas the client wishes to keep as many changes as possible under 'design development' to minimize cost escalation. This may most likely be the largest potential area exposed to disputation, particularly if the target cost is confirmed during the early design stage (Tay et al. 2000). Besides, the extent of design development variations would also be difficult to define. Further crucial to the GMP/TCC scheme is the development of an effective, efficient adjudication process via the adjudication committee to report on the status of a variation submission and to determine the classification of various variations submitted by the contractor (Hong Kong Housing Authority 2006). It is also vital to reach a mutual agreement on the valuation of variations 
as prompt as possible in order not to disturb the overall progress of the project.

As indicated in Table 7, other significant difficulties encountered in adopting GMP/TCC, with mean value larger than 3, consisted of Item 4 'Lack of standard form of GMP/TCC contract in the local context' (Gander and Hemsley 1997); Item 12 'Not suitable for projects where it is difficult to define the scope of work early' (Chevin 1996); Item 2 'Increased commitment and involvement by project managers and design consultants in evaluating tenders for domestic subcontracts after the award of main contract leading to the potential for incurring higher consultant fees' (Tang and Lam 2003); Item 5 'Longer time in preparing contract documents'; and Item 6 'Unfamiliarity with or misunderstanding of GMP/TCC concepts by senior management' (Chan et al. 2007). Project decision-makers should place particular focus on the above difficulties identified before deciding to use the GMP/TCC form of procurement strategy.

\section{Agreement of respondents within each survey group}

Analogous to the previous 'risk factors' section, the potential difficulties of GMP/TCC were further investigated by testing the disparity of the rankings rated by the client group, contractor group and consultant group individually. As reflected from Table 7, the Kendall's coefficient of concordance $(W)$ for the rankings of difficulties was $0.300,0.379$, 0.313 and 0.313 for 'all respondent group', 'client group', 'contractor group' and 'consultant group' respectively. The computed $W$ 's were all significant with $p=0.000$.

As pointed out by Siegel and Castellan (1988), the chi-square value would be adopted instead of the $W$ value since the number of factors investigated was larger than seven. According to the degree of freedom $(12-1=11)$ and the allowable level of significance [5\% as adopted by Chan et al. (2003)], the critical value of chi-square from table was found to be 19.68. For all of the four groups ('all respondent group', 'client group', 'contractor group' and 'consultant group'), the actual computed chi-square values (115.50, $50.03,44.76$ and 34.43 respectively) were all above the critical value of chi-square of 19.68. This result leads to the rejection of the null hypothesis that 'There is no significant agreement amongst different respondents on the rankings within a particular group'. Hence, there is sufficient evidence to conclude that there is significant degree of agreement amongst the respondents within each group on the rankings of the difficulties of 
GMP/TCC.

\section{Agreement of respondents between survey groups}

After the internal consensus of the rankings within all respondent group and within each of the three respondent groups was confirmed, the level of agreement amongst the groups of survey respondents on the ranking exercise was further explored via the Spearman's rank correlation test as depicted in Table 8. The null hypotheses that no significant correlation between clients-contractors, clients-consultants and contractors-consultants on the rankings of GMP/TCC difficulties can be rejected. Thus, there is adequate evidence to conclude that there is no significant disagreement between any two groups on the ranking exercise. This reflects the apparent unanimous consensus on the perceptions of the difficulties with the GMP/TCC approach amongst the three respondent groups.

For example, there was considerable agreement across all of the three contracting parties that the GMP/TCC form of procurement is vulnerable in the necessity to keep pace the design development with main contractor's program for tendering the domestic subcontractor's works packages, and the greater involvement of client throughout the whole project delivery process (both factors ranked as either 1st or 2nd). The results are in line with the findings reported by Sadler (2004) and the Hong Kong Housing Authority (2006). Merely by direct observation, the client group ranked Item 2 'Increased commitment and involvement by project managers and design consultants in evaluating tenders for domestic subcontracts i.e. potential for incurring higher consultant fees' noticeably lower (9th) than the other two groups (3rd for contractor group and 4th for consultant group). This diverse perception may be due to the fact that the tender evaluation of domestic subcontractors is primarily undertaken by the team of consultants together with main contractor's project manager rather than the client himself, so the client does not perceive it as a major difficulty at all.

Table 6. Potential difficulties of GMP/TCC in Hong Kong (all respondents)

Table 7. Ranking and Kendall's coefficient of concordance for the potential difficulties of GMP/TCC 
Table 8. Spearman's rank correlation test between groups of survey respondents on the potential difficulties of GMP/TCC

\section{Conclusions}

Based on an extensive review of published literature and an empirical questionnaire survey conducted with relevant experienced industrial practitioners in Hong Kong, this research study has generated an in-depth analysis of the possible pitfalls (including key risk factors and potential difficulties) associated with the GMP/TCC scheme in comparison with other procurement strategies. A total of 45 valid completed survey forms were received for further statistical analysis and cross-comparisons amongst various key survey groups. Both the key risk factors and potential obstacles which might impede the success of GMP/TCC construction projects were critically identified, evaluated, analyzed and discussed with the assistance of various statistical tools.

The empirical survey findings reflected that: (1) Involvement of any inexperienced or claim-conscious contractors in the project delivery process; (2) Disputes arising from changes in the scope of work; and (3) Unforeseen design development risks, were regarded as the top three risk factors inherent with the GMP/TCC contractual arrangement. Furthermore, (1) Keeping design development in pace with the main contractor's program for tendering the domestic subcontractors' works packages; (2) More involvement by the clients in a project; and (3) Disputes over whether Architects/Engineers Instructions constituted GMP/TCC variations or were deemed to be design development, were also perceived to be the three most significant difficulties encountered with GMP/TCC.

The GMP/TCC form of procurement can be an effective means of motivating contractors to achieve better value and more favorable project performance by aligning their own financial objectives with the overall objectives of the project (Construction Industry Review Committee 2001). Since GMP/TCC is still at a germinating stage of development in Hong Kong, such an industry-wide investigation of the major risk factors and potential difficulties encountered is timely and indispensable, especially in the local context. The survey results have provided strong evidence and useful pointers to assist key project stakeholders in mitigating the hindrances caused by potential risks or difficulties in order to make GMP/TCC succeed. The research study has also made substantial contributions to 
new knowledge and practical information of GMP/TCC applications and implementation for the whole construction industry, so as to drive for excellence in overall project performance.

By mitigating the impact of risk factors and the occurrence of potential difficulties, more applications of GMP/TCC form of procurement across a wide spectrum of the construction industry should be encouraged for completing projects within schedule, within budget, with higher quality and fewer disputes or claims. Another on-going research project (Chan et al. 2008) focusing on the identification, analysis, allocation and mitigation of key risk factors, as well as the evaluation of various risk sharing mechanisms for GMP/TCC projects, is underway in Hong Kong and the key research findings will be reported in later publications.

\section{Acknowledgements}

The authors wish to express their heartfelt gratitudes to all the individuals who have kindly participated in the empirical questionnaire survey undertaken between May and June of 2007 in Hong Kong for offering their valuable opinions and necessary project information to make this study possible. Financial support from the Department of Building and Real Estate of The Hong Kong Polytechnic University to this research initiative (HK PolyU BRE Departmental General Research Grants Allocation 2006/07 with Project Account Code: BRE-G-U252) is also gratefully acknowledged. The work described in this paper was further supported by another grant from the Research Grants Council of the Hong Kong Special Administrative Region, China (RGC Project No. PolyU 5107/07E).

This paper forms part of a RGC funded research project entitled "Evaluating the Key Risk Factors and Risk Sharing Mechanisms for Target Cost Contracting (TCC) Schemes in Construction" with several objectives sharing common background of study and research methodology. Contributions from Dr James Wong to the initial draft of this paper are greatly appreciated while he was still in employment with The Hong Kong Polytechnic University. Additionally, the helpful comments and valuable suggestions from both the editor and the three anonymous reviewers are respectfully acknowledged in that they help to improve the overall quality of this paper. 


\section{References}

Baldwin, A.N. and McCaffer, R. (1991) Estimating and Tendering for Civil Engineering Works, 2nd Edition, Oxford: BSP Professional Books.

Broome, J.C. and Perry, J.G. (1995) Experiences of the use of the New Engineering Contract, Engineering, Construction and Architectural Management, 2(4), 271-285.

Broome, J. and Perry, J. (2002) How practitioners set share fractions in target cost contracts, International Journal of Project Management, 20(1), 59-66.

Cantirino, J. and Fodor, S. (2003) Construction delivery systems in the United States. Journal of Corporate Real Estate, 5(2), 169-177.

Carty, G.J. (1995) Construction. Journal of Construction Engineering and Management, ASCE, 121(3), 319-328.

Chan, A.P.C. (1998) Perception on variations - a tale of three cities. The Australian Institute of Quantity Surveyors Refereed Journal, 2(1), $42-54$.

Chan, A.P.C., Chan, D.W.M. and Ho, K.S.K. (2002) An Analysis of Project Partnering in Hong Kong. Research Monograph, Department of Building and Real Estate, The Hong Kong Polytechnic University, 96 pages, ISBN 962-367-363-9, October 2002.

Chan, A.P.C., Chan, D.W.M. and Ho, K.S.K. (2003) An empirical study of the benefits of construction partnering in Hong Kong. Construction Management and Economics, 21(5), 523-533.

Chan, D.W.M., Chan, A.P.C., Lam, P.T.I., Lam, E.W.M. and Wong, J.M.W. (2007) Evaluating guaranteed maximum price and target cost contracting strategies in Hong Kong construction industry. Journal of Financial Management of Property and Construction, 12(3), 139-149.

Chan, D.W.M., Chan, A.P.C., Lam, P.T.I., Chan, J.H.L., Hughes, Will and Ma, Tony. (2008) A research framework for exploring risk allocation mechanisms for target cost contracts in construction. Proceedings of the CRIOCM 2008 International Research Symposium on Advancement of Construction Management and Real Estate, 31 October - 3 November 2008, Beijing, China, 289-296.

Chan, D.W.M. and Kumaraswamy, M.M. (1996) An evaluation of construction time performance in the building industry. Building and Environment, 31(6), 569-578. 
Cheng, R.L.L. (2004) Investigation of the Application of Guaranteed Maximum Price in the Hong Kong Construction Industry. Unpublished BSc(Hons) Dissertation in Construction Economics and Management, Department of Building and Real Estate, The Hong Kong Polytechnic University, Hong Kong, 58 pages.

Chevin, D. (1996) The max factor. Building, 17 May 1996.

Clough, R.H. and Sears, G.A. (1994) Construction Contracting, 6th Edition, New York, Wiley-Interscience Publication.

Construction Industry Review Committee (2001) Construct for Excellence. Report of the Construction Industry Review Committee, Hong Kong SAR, 207 pages.

Daniel, W.W. (1978) Applied Nonparametric Statistics, Houghton Mifflin, Boston.

Fan, A.C.W. and Greenwood, D. (2004) Guaranteed maximum price for the project? Surveyors Times, The Hong Kong Institute of Surveyors, March, 20-21.

Gander, A. and Hemsley, A. (1997) Guaranteed maximum price contracts. CSM, January, 38-39.

Hong Kong Housing Authority (2006) Internal Guidelines for Guaranteed Maximum Price Contract Procurement Based on Private Sector Model. The Hong Kong Housing Authority, Hong Kong SAR Government, 19 pages.

Lewis, D. (2002) Dispute resolution in the New Hong Kong International Airport Core Programme Projects - postscripts. The International Construction Law Review, January 2002.

Masterman, J.W.E. (2002) Introduction to Building Procurement System, 2nd Edition, London Spon Press.

Mills, R.S. and Harris, E.C. (1995) Guaranteed maximum price contracts. Construction Law, 573/95, 28-31.

Minogue, A. (1998) Firms reject GMP contracts. Building, May 1998.

National Economic Development Office (1982) Target Cost Contracts - A Worthwhile Alternative. Civil Engineering Economic Development Committee, National Economic Development Office, UK: London.

Norusis, M.J. (2002) SPSS 11.0 Guide to Data Analysis, Upper Saddle River, New Jersey: Prentice Hall.

Patterson, L. (1999) Legal - the trouble with GMP. Building, Volume 49.

Perry, J.G. (1995) The New Engineering Contract: principles of design and risk allocation, Engineering, Construction and Architectural Management, 2(3), 197-208. 
Perry, J.G. and Barnes, M. (2000) Target cost contracts: an analysis of the interplay between fee, target, share and price. Engineering, Construction and Architectural Management, 7(2), 202-208.

Sadler, M.C. (2004) The Use of Alternative Integrated Procurement Approaches in the Construction Industry. Unpublished MBA Dissertation in Construction and Real Estate, Department of Construction Management and Engineering, University of Reading, UK, 132 pages.

Sanotos, J.R.A. (1999) Cronbach's alpha: a tool for assessing the reliability of scales. Journal of Extension, 37(2), 1-5.

Siegel, S. and Castellan Jr, N. J. (1988) Nonparametric Statistics for Behavioural Sciences. 2nd Edition, McGraw-Hill, New York.

Stuckhart, G. (1984) Contractual incentives. Journal of Construction Engineering and Management, ASCE, 110(1), 34-42.

Tang, S.L. and Lam, R.W.T. (2003) Applying the target cost contract concept to price adjustments for design-and-build contracts. Hong Kong Engineer, September, 18-19.

Tang, W.Y. (2005) An Evaluation of the Success and Limitations of Guaranteed Maximum Price in the Hong Kong Construction Industry. Unpublished BSc(Hons) Dissertation in Construction Economics and Management, Department of Building and Real Estate, The Hong Kong Polytechnic University, Hong Kong, 41 pages.

Tay, P., McCauley, G. and Bell, B. (2000) Meeting client's needs with GMP. The Building Economist, June 2000, 4-5.

Trench, D. (1991) On Target - A Design and Manage Target Cost Procurement System. London Thomas Telford.

Uebergang, K., Galbraith, V. and Tam, A.M.L. (2004) Sustainable Construction Innovations in Action. Civic Exchange Limited, February 2004.

Walker, D.H.T., Hampson, K.D. and Peters, R. (2000) Relationship-based Procurement Strategies for the 21st Century. AusInfo, Canberra, Australia, ISBN 064243079-9, 112 pages. 
Table 1. Summary of the key risks of GMP/TCC

\section{Key risks of GMP/TCC}

\begin{tabular}{|c|c|c|c|c|c|c|c|c|c|c|c|c|c|}
\hline Financial risks & & & & & & & & & & & & & \\
\hline $\begin{array}{l}\text { The client may pay more than the ceiling price due to the } \\
\text { change in scope of work. }\end{array}$ & $\checkmark$ & $\checkmark$ & $\checkmark$ & & $\checkmark$ & $\checkmark$ & & & & $\checkmark$ & $\checkmark$ & & 7 \\
\hline $\begin{array}{l}\text { Contractor may earn lower profit or even incur a loss due to } \\
\text { unclear definition of scope of work. }\end{array}$ & & $\checkmark$ & $\checkmark$ & $\checkmark$ & & & & & $\checkmark$ & & & $\checkmark$ & 5 \\
\hline Contractor bears any unforeseen design development risks. & & $\checkmark$ & $\checkmark$ & $\checkmark$ & $\checkmark$ & & $\checkmark$ & & $\sqrt{ }$ & $\checkmark$ & $\checkmark$ & $\checkmark$ & 9 \\
\hline Dispute risks & & & & & & & & & & & & & \\
\hline Disputes may arise due to the change in scope of work. & $\sqrt{ }$ & $\checkmark$ & & $\checkmark$ & $\checkmark$ & & $\checkmark$ & $\checkmark$ & & & & & 6 \\
\hline $\begin{array}{l}\text { Inexperienced or claim-conscious contractors may } \\
\text { jeopardize GMP/TCC process. }\end{array}$ & $\checkmark$ & $\checkmark$ & $\checkmark$ & & & & & & & & & & 3 \\
\hline $\begin{array}{l}\text { Lack of standard form of GMP/TCC contract leads to } \\
\text { misunderstanding of liabilities between various contracting } \\
\text { parties. }\end{array}$ & & & $\checkmark$ & & & & & & & $\checkmark$ & & & 2 \\
\hline $\begin{array}{l}\text { Total number of risk factors identified from each } \\
\text { publication }\end{array}$ & 3 & 5 & 5 & 3 & 3 & 1 & 2 & 1 & 2 & 3 & 2 & 2 & 32 \\
\hline
\end{tabular}

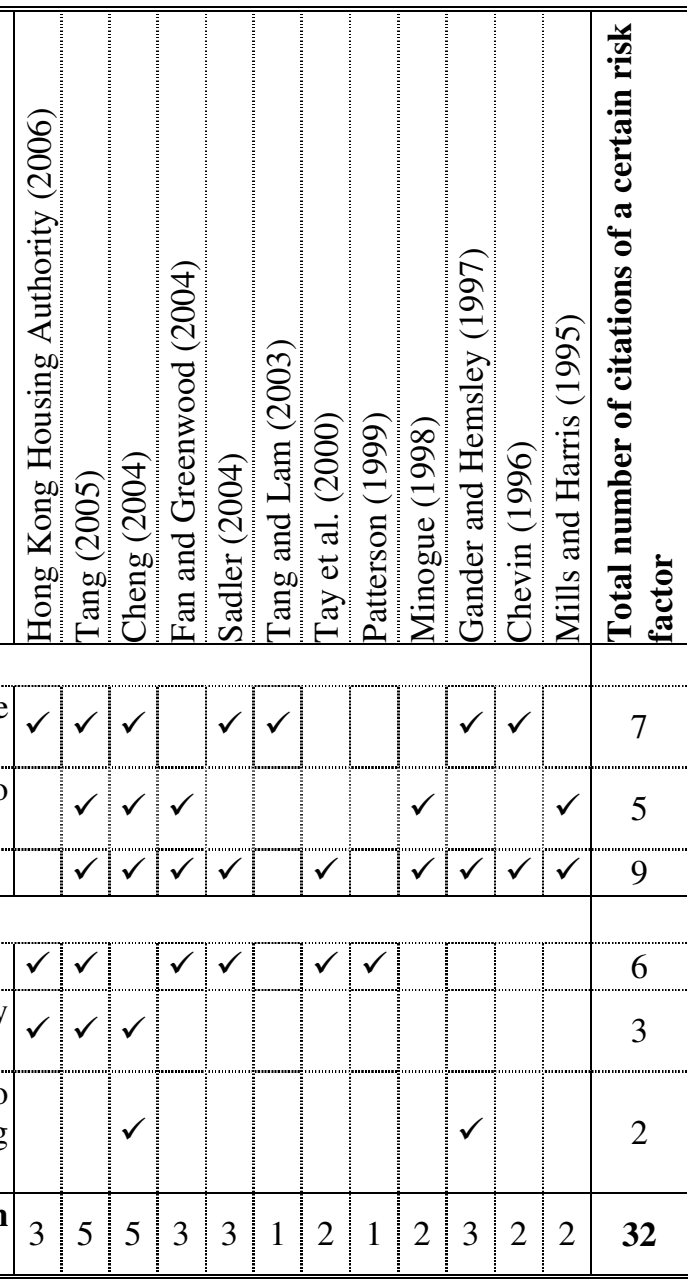

Note: The previous studies are listed in decreasing chronological order of year of publication followed by the alphabetical order of the authors' surnames. 
Table 2. Summary of the potential difficulties in implementing GMP/TCC

\section{Potential difficulties in implementing GMP/TCC}

Unclear definition of change in scope of work leading to unnecessary disputes

Difficult to evaluate the revised contract price when an alternative design is proposed by the contractor Higher costs to adopt GMP/TCC for contractor to cover additional risks

\begin{tabular}{|c|c|c|c|c|c|c|c|c|c|c|c|c|c|c|}
\hline $\begin{array}{l}\text { Increased commitment and involvement by project } \\
\text { managers and design consultants in evaluating tenders for } \\
\text { domestic subcontracts after the award of main contract }\end{array}$ & $\checkmark$ & & & & & $\checkmark$ & & & & & & & & 2 \\
\hline $\begin{array}{l}\text { Design development must keep pace with main contractor's } \\
\text { programme for tendering domestic subcontractor's works } \\
\text { packages otherwise potential delay may occur }\end{array}$ & $\checkmark$ & & & & & & & & & & & & & 1 \\
\hline $\begin{array}{l}\text { Lack of standard form of GMP/TCC building contract in } \\
\text { Hong Kong }\end{array}$ & & & & & & & & & & & $\checkmark$ & & & 1 \\
\hline $\begin{array}{l}\text { Unfamiliarity with or misunderstanding of GMP/TCC } \\
\text { concepts by project stakeholders }\end{array}$ & & $\checkmark$ & $\checkmark$ & & $\checkmark$ & & & & & & & & & 3 \\
\hline Too complicated form of contractual agreement & & & & & $\checkmark$ & & & & & & & & & 1 \\
\hline $\begin{array}{l}\text { Total number of difficulties identified from each } \\
\text { publication }\end{array}$ & 3 & 3 & 2 & 1 & 5 & 2 & 1 & 3 & 1 & 1 & 3 & 1 & 2 & 28 \\
\hline
\end{tabular}

Note: The previous studies are listed in decreasing chronological order of year of publication followed by the alphabetical order of the authors' surnames. 
Table 3. Key risk factors of GMP/TCC in Hong Kong (all respondents)

\begin{tabular}{|c|c|c|c|}
\hline Risk factors of GMP/TCC & $\mathbf{N}$ & Mean ${ }^{\#}$ & $\begin{array}{l}\text { Standard } \\
\text { Deviation } \\
\quad \text { (SD) }\end{array}$ \\
\hline 1. Disputes may arise due to the change in the scope of work. & 45 & 3.80 & 0.869 \\
\hline $\begin{array}{l}\text { 2. Difficult to evaluate the revised contract price when an alternative } \\
\text { design is proposed by the contractor and it takes time to reassess the } \\
\text { cost of the entire project. }\end{array}$ & 45 & 3.13 & 1.036 \\
\hline $\begin{array}{l}\text { 3. Inexperienced or claim-conscious contractors jeopardize the } \\
\text { GMP/TCC process. }\end{array}$ & 44 & 3.89 & 0.895 \\
\hline $\begin{array}{l}\text { 4. The client may pay more because contractor may inflate the estimated } \\
\text { costs to cover his additional risks. }\end{array}$ & 45 & 2.93 & 1.009 \\
\hline $\begin{array}{l}\text { 5. Contractor may earn lower profit or even incur a loss due to unclear } \\
\text { definition of the scope of work. }\end{array}$ & 44 & 3.45 & 1.022 \\
\hline $\begin{array}{l}\text { 6. No standard form of GMP/TCC contract leads to misunderstanding of } \\
\text { liabilities between parties. }\end{array}$ & 45 & 3.49 & 0.920 \\
\hline $\begin{array}{l}\text { 7. Difficult to use successfully on contracts where many changes are } \\
\text { expected. }\end{array}$ & 45 & 3.38 & 1.211 \\
\hline $\begin{array}{l}\text { 8. Contractor may not foresee design development risks thus taking } \\
\text { more risks. }\end{array}$ & 45 & 3.60 & 0.939 \\
\hline $\begin{array}{l}\text { 9. Client may carry more risks than the traditional procurement approach } \\
\text { because of incomplete design at tender stage. }\end{array}$ & 45 & 2.69 & 0.925 \\
\hline $\begin{array}{l}\text { 10. Variations may cost more than under the traditional procurement } \\
\text { approach. }\end{array}$ & 45 & 2.53 & 0.815 \\
\hline
\end{tabular}

Note: Items were rated on a 5-point Likert scale with $1=$ strongly disagree; $3=$ neutral and $5=$ strongly agree. 
Table 4. Ranking and Kendall's coefficient of concordance for the key risk factors of GMP/TCC

\begin{tabular}{|c|c|c|c|c|c|c|c|c|c|}
\hline \multirow[b]{2}{*}{ ID } & \multirow[b]{2}{*}{ Risk factors of GMP/TCC } & \multicolumn{2}{|c|}{$\begin{array}{l}\text { All respondent } \\
\text { group }\end{array}$} & \multicolumn{2}{|c|}{$\begin{array}{l}\text { Client } \\
\text { group }\end{array}$} & \multicolumn{2}{|c|}{$\begin{array}{l}\text { Contractor } \\
\text { group }\end{array}$} & \multicolumn{2}{|c|}{$\begin{array}{c}\text { Consultant } \\
\text { group }\end{array}$} \\
\hline & & Mean & Rank & Mean & Rank & Mean & Rank & Mean & Rank \\
\hline 3 & $\begin{array}{l}\text { Inexperienced or claim-conscious contractors } \\
\text { jeopardize the GMP/TCC process. }\end{array}$ & 3.89 & 1 & 3.60 & 1 & 3.88 & 4 & 4.23 & 1 \\
\hline 1 & $\begin{array}{l}\text { Disputes may arise due to the change in the } \\
\text { scope of work. }\end{array}$ & 3.80 & 2 & 3.47 & 2 & 4.00 & 1 & 3.92 & 2 \\
\hline 8 & $\begin{array}{l}\text { Contractor may not foresee design development } \\
\text { risks thus taking more risks. }\end{array}$ & 3.64 & 3 & 3.47 & 3 & 3.75 & 6 & 3.69 & 3 \\
\hline 6 & $\begin{array}{l}\text { No standard form of GMP/TCC contract leads to } \\
\text { misunderstanding of liabilities between parties. }\end{array}$ & 3.50 & 4 & 3.00 & 8 & 4.00 & 1 & 3.46 & 4 \\
\hline 5 & $\begin{array}{l}\text { Contractor may earn lower profit or even incur a } \\
\text { loss due to unclear definition of the scope of } \\
\text { work. }\end{array}$ & 3.45 & 5 & 3.00 & 7 & 4.00 & 1 & 3.31 & 5 \\
\hline 7 & $\begin{array}{l}\text { Difficult to use successfully on contracts where } \\
\text { many changes are expected. }\end{array}$ & 3.41 & 6 & 3.40 & 4 & 3.81 & 5 & 2.92 & 8 \\
\hline 2 & $\begin{array}{l}\text { Difficult to evaluate the revised contract price } \\
\text { when an alternative design is proposed by the } \\
\text { contractor and it takes time to reassess the cost } \\
\text { of the entire project. }\end{array}$ & 3.09 & 7 & 3.07 & 6 & 3.00 & 7 & 3.23 & 6 \\
\hline 4 & $\begin{array}{l}\text { The client may pay more because contractor } \\
\text { may inflate the estimated costs to cover his } \\
\text { additional risks. }\end{array}$ & 2.95 & 8 & 2.67 & 9 & 3.00 & 7 & 3.23 & 6 \\
\hline 9 & $\begin{array}{l}\text { Client may carry more risks than the traditional } \\
\text { procurement approach because of incomplete } \\
\text { design at tender stage. }\end{array}$ & 2.70 & 9 & 3.20 & 5 & 2.25 & 10 & 2.69 & 9 \\
\hline 10 & $\begin{array}{l}\text { Variations may cost more than under the } \\
\text { traditional procurement approach. }\end{array}$ & 2.50 & 10 & 2.47 & 10 & 2.56 & 9 & 2.46 & 10 \\
\hline & $\operatorname{Number}(\mathrm{N})$ & \multicolumn{2}{|c|}{44} & \multicolumn{2}{|c|}{15} & \multicolumn{2}{|c|}{16} & \multicolumn{2}{|c|}{13} \\
\hline & Kendall's coefficient of concordance (W) & \multicolumn{2}{|c|}{0.249} & \multicolumn{2}{|c|}{0.173} & \multicolumn{2}{|c|}{0.445} & \multicolumn{2}{|c|}{0.332} \\
\hline & Actual calculated chi-square value & \multicolumn{2}{|c|}{98.60} & \multicolumn{2}{|c|}{23.36} & \multicolumn{2}{|c|}{64.08} & \multicolumn{2}{|c|}{38.84} \\
\hline & Critical value of chi-square from table & \multicolumn{2}{|c|}{16.92} & \multicolumn{2}{|c|}{16.92} & \multicolumn{2}{|c|}{16.92} & \multicolumn{2}{|c|}{16.92} \\
\hline & Degree of freedom (df) & \multicolumn{2}{|c|}{9} & \multicolumn{2}{|c|}{9} & \multicolumn{2}{|c|}{9} & \multicolumn{2}{|c|}{9} \\
\hline & Asymptotic level of significance & \multicolumn{2}{|c|}{0.000} & \multicolumn{2}{|c|}{0.005} & \multicolumn{2}{|c|}{0.000} & \multicolumn{2}{|c|}{0.000} \\
\hline & $\begin{array}{l}\mathrm{H}_{0}=\text { Respondents' sets of rankings are unrelate } \\
\text { Reject } \mathrm{H}_{0} \text { if the actual chi-square value is larger }\end{array}$ & net & $n t) \mathrm{t}$ & the & thi & gro & & & \\
\hline
\end{tabular}


Table 5. Spearman's rank correlation test between groups of survey respondents on the key risk factors of GMP/TCC

\begin{tabular}{|c|c|c|c|}
\hline $\begin{array}{c}\begin{array}{c}\text { Comparison of rankings between groups } \\
\text { of survey respondents }\end{array} \\
\end{array}$ & $\mathbf{r}_{\mathrm{s}}$ & $\begin{array}{c}\text { Significance } \\
\text { level }\end{array}$ & Conclusion \\
\hline Client ranking vs Contractor ranking & 0.320 & 0.367 & $\begin{array}{c}\text { Cannot reject } \mathrm{H}_{0} \text { at } 5 \% \\
\text { significance level }\end{array}$ \\
\hline Client ranking vs Consultant ranking & 0.644 & 0.044 & $\begin{array}{l}\text { Reject } \mathrm{H}_{0} \text { at } 5 \% \\
\text { significance level }\end{array}$ \\
\hline Contractor ranking vs Consultant ranking & 0.728 & 0.017 & $\begin{array}{l}\text { Reject } \mathrm{H}_{0} \text { at } 5 \% \\
\text { significance level }\end{array}$ \\
\hline
\end{tabular}

Table 6. Potential difficulties of GMP/TCC in Hong Kong (all respondents)

Difficulties in implementing GMP/TCC

1. Disputes over whether Architects/Engineers Instructions constituted GMP/TCC variations or were deemed to be design development, i.e. unclear scope of work.

2. Increased commitment and involvement by project managers and design consultants in evaluating tenders (mainly on technical elements) for domestic subcontracts after the award of main contract, i.e. potential for incurring higher consultant fees.

3. Design development must keep pace with main contractor's program for tendering the domestic subcontractor's works packages otherwise potential delay may result.

4. Lack of standard form of GMP/TCC contract in the local context.

5. Longer time in preparing contract documents.

6. Unfamiliarity with or misunderstanding of GMP/TCC concepts by senior management.

7. Difficult to develop trust and understanding from contractor as a project team.

8. Too complicated form of contractual agreement.

9. Difficult to launch subcontracting with back-to-back contract terms.

10. Clients had to be more involved in a project.

11. A project team may find it difficult to adapt to this new way of working.

12. Not suitable for projects where it is difficult to define the scope of work early.

\begin{tabular}{|c|c|c|}
\hline $\mathbf{N}$ & Mean $^{\#}$ & $\begin{array}{c}\text { Standard } \\
\text { Deviation } \\
\text { (SD) } \\
\end{array}$ \\
\hline 39 & 3.79 & 0.910 \\
\hline 39 & 3.46 & 0.854 \\
\hline 39 & 4.03 & 0.628 \\
\hline 39 & 3.69 & 0.950 \\
\hline 39 & 3.28 & 0.972 \\
\hline 39 & 3.10 & 1.021 \\
\hline 40 & 2.50 & 1.013 \\
\hline 41 & 2.61 & 0.919 \\
\hline 40 & 2.50 & 0.816 \\
\hline 41 & 4.02 & 0.758 \\
\hline 41 & 2.90 & 0.995 \\
\hline 41 & 3.39 & 1.202 \\
\hline
\end{tabular}

Note: Items were rated on a 5-point Likert scale with $1=$ strongly disagree; $3=$ neutral and $5=$ strongly agree. 
Table 7. Ranking and Kendall's coefficient of concordance for the potential difficulties of GMP/TCC

\begin{tabular}{|c|c|c|c|c|c|c|c|c|c|}
\hline \multirow[b]{2}{*}{ ID } & \multirow[b]{2}{*}{ Difficulties in implementing GMP/TCC } & \multicolumn{2}{|c|}{$\begin{array}{l}\text { All respondent } \\
\text { group }\end{array}$} & \multicolumn{2}{|c|}{$\begin{array}{l}\text { Client } \\
\text { group }\end{array}$} & \multicolumn{2}{|c|}{$\begin{array}{c}\text { Contractor } \\
\text { group }\end{array}$} & \multicolumn{2}{|c|}{$\begin{array}{c}\text { Consultant } \\
\text { group }\end{array}$} \\
\hline & & Mean & & Mean & Rank & Mean & Rank & Mean & Rank \\
\hline 3 & $\begin{array}{l}\text { Design development must keep pace with main } \\
\text { contractor's programme for tendering the } \\
\text { domestic subcontractor's works packages } \\
\text { otherwise potential delay may result. }\end{array}$ & 4.03 & 1 & 4.00 & 2 & 4.15 & 1 & 3.90 & 1 \\
\hline 10 & Clients had to be more involved in a project & 3.97 & 2 & 4.33 & 1 & 3.85 & 2 & 3.70 & 2 \\
\hline 1 & $\begin{array}{l}\text { Disputes over whether Architects/Engineers } \\
\text { Instructions constituted GMP/TCC variations } \\
\text { or were deemed to be design development, i.e. } \\
\text { unclear scope of work. }\end{array}$ & 3.63 & 3 & 3.58 & 4 & 3.69 & 3 & 3.60 & 3 \\
\hline 4 & $\begin{array}{l}\text { Lack of standard form of GMP/TCC contract } \\
\text { in the local context. }\end{array}$ & 3.57 & 4 & 3.75 & 3 & 3.62 & 6 & 3.30 & 5 \\
\hline 12 & $\begin{array}{l}\text { Not suitable for projects where it is difficult to } \\
\text { define the scope of work early. }\end{array}$ & 3.43 & 5 & 3.33 & 6 & 3.69 & 3 & 3.20 & 6 \\
\hline 2 & $\begin{array}{l}\text { Increased commitment and involvement by } \\
\text { project managers and design consultants in } \\
\text { evaluating tenders (mainly on technical } \\
\text { elements) for domestic subcontracts after the } \\
\text { award of main contract, i.e. potential for } \\
\text { incurring higher consultant fees. }\end{array}$ & 3.40 & 6 & 3.00 & 9 & 3.69 & 3 & 3.50 & 4 \\
\hline 5 & Longer time in preparing contract documents. & 3.17 & 7 & 3.42 & 5 & 3.23 & 7 & 2.80 & 8 \\
\hline 6 & $\begin{array}{l}\text { Unfamiliarity with or misunderstanding of } \\
\text { GMP/TCC concepts by senior management. }\end{array}$ & 3.17 & 7 & 3.25 & 8 & 3.08 & 8 & 3.20 & 6 \\
\hline 11 & $\begin{array}{l}\text { A project team may find it difficult to adapt to } \\
\text { this new way of working. }\end{array}$ & 2.91 & 9 & 3.33 & 6 & 2.77 & 10 & 2.60 & 9 \\
\hline 8 & $\begin{array}{l}\text { Too complicated form of contractual } \\
\text { agreement. }\end{array}$ & 2.57 & 10 & 2.42 & 10 & 2.85 & 9 & 2.40 & 11 \\
\hline 7 & $\begin{array}{l}\text { Difficult to develop trust and understanding } \\
\text { from contractor as a project team. }\end{array}$ & 2.49 & 11 & 2.42 & 10 & 2.77 & 10 & 2.20 & 12 \\
\hline 9 & $\begin{array}{l}\text { Difficult to launch subcontracting with back- } \\
\text { to-back contract terms. }\end{array}$ & 2.49 & 11 & 2.33 & 12 & 2.54 & 12 & 2.60 & 9 \\
\hline & Number $(\mathrm{N})$ & \multicolumn{2}{|c|}{35} & \multicolumn{2}{|c|}{12} & \multicolumn{2}{|c|}{13} & \multicolumn{2}{|c|}{10} \\
\hline & Kendall's coefficient of concordance (W) & \multirow{2}{*}{\multicolumn{2}{|c|}{0.300}} & \multicolumn{2}{|c|}{0.379} & \multicolumn{2}{|c|}{0.313} & \multicolumn{2}{|c|}{0.313} \\
\hline & Actual calculated chi-square value & & & \multirow{2}{*}{\multicolumn{2}{|c|}{$\begin{array}{l}50.03 \\
19.68\end{array}$}} & \multirow{2}{*}{\multicolumn{2}{|c|}{$\frac{44.76}{1968}$}} & \multirow{2}{*}{\multicolumn{2}{|c|}{$\frac{34.43}{1968}$}} \\
\hline & Critical value of chi-square from table & \multicolumn{2}{|c|}{$\begin{array}{c}115.50 \\
19.68\end{array}$} & & & & & & \\
\hline & Degree of freedom (df) & \multicolumn{2}{|c|}{11} & \multicolumn{2}{|c|}{11} & \multicolumn{2}{|c|}{11} & \multicolumn{2}{|c|}{11} \\
\hline & Asymptotic level of significance & \multicolumn{2}{|c|}{0.000} & \multicolumn{2}{|c|}{0.000} & \multicolumn{2}{|c|}{0.000} & \multicolumn{2}{|c|}{0.000} \\
\hline
\end{tabular}

Table 8. Spearman's rank correlation test between groups of survey respondents on the potential difficulties of GMP/TCC

\begin{tabular}{|c|c|c|c|}
\hline \hline $\begin{array}{c}\text { Comparison of rankings between groups } \\
\text { of survey respondents }\end{array}$ & $\mathbf{r}_{\mathrm{s}}$ & $\begin{array}{c}\text { Significance } \\
\text { level }\end{array}$ & Conclusion \\
\hline Client ranking vs Contractor ranking & 0.772 & 0.003 & $\begin{array}{c}\text { Reject } \mathrm{H}_{0} \text { at } 1 \% \\
\text { significance level }\end{array}$ \\
\hline Client ranking vs Consultant ranking & 0.785 & 0.002 & $\begin{array}{c}\text { Reject } \mathrm{H}_{0} \text { at } 1 \% \\
\text { significance level }\end{array}$ \\
\hline Contractor ranking vs Consultant ranking & 0.912 & 0.000 & $\begin{array}{c}\text { Reject } \mathrm{H}_{0} \text { at } 1 \% \\
\text { significance level }\end{array}$ \\
\hline $\begin{array}{l}\mathrm{H}_{0}=\text { No significant correlation on the rankings between two groups } \\
\mathrm{H}_{\mathrm{a}}=\mathrm{Significant}_{\mathrm{s}} \text { correlation on the rankings between two groups } \\
\text { Reject } \mathrm{H}_{0} \text { if the actual significance level (p-value) is less than the allowable value of } 5 \%\end{array}$ \\
\hline \hline
\end{tabular}

